\title{
Larger Basket of Choice to Reduce Family Planning Unmet Need Introducing a New Long-Acting Reversible Contraceptive Method in MOROCCO
}

\author{
Shible Sahbani ${ }^{1 *}$, Laila Acharai ${ }^{2}$, Hafida Yartaoui ${ }^{3}$ and Rachid Bezzad ${ }^{4}$ \\ ${ }^{1}$ Regional Reproductive Health Adviser, United Nations Population Fund, USA \\ ${ }^{2}$ Reproductive Health Analyst, United Nations Population Fund, Morocco \\ ${ }^{3}$ Manager of the National Family Planning Programme. MoH, Morocco \\ ${ }^{4}$ Director of the National Reproductive Health Centre, Morocco \\ Submission: April 27, 2019 ; Published: May 03, 2019
}

*Corresponding author: Shible Sahbani, Family planning, Regional Reproductive Health Adviser, USA

Keywords: Family planning; LARC; Long-Acting Reversible Contraceptives; UNFPA Morocco; FP unmet need; Implant

Abbrevations: NFPP: National Family Planning Program; CPR: Contraceptive Prevalence Rate; TFR: Total Fertility Rate; MMR: Maternal Mortality Ratio; CRSR: Reproductive Health Referral Center; UNFPA: United Nations Population Fund

\section{Problem and Context}

Morocco made a great progress in its National Family Planning Program (NFPP) over the past three decades. According to data from the National Population and Family Health Survey (ENPSF 2018 ): the contraceptive prevalence rate (CPR) is 70.8 percent, the use of modern methods is 58.0 percent, the family planning unmet need is 13.8 percent; and the total fertility rate (TFR) is 2.38 children per woman. The high contraceptive use contributed considerably to the reduction of Morocco's Maternal Mortality Ratio (MMR), down from 332 deaths per 100,000 live births in 1990 to 72.6 in 2017.

The NFPP has reinforced the delivery of FP in primary health centersin an integrated service package, targeting the improvement of quality of care. The range of contraceptive methods available includes four modern methods (pills, injectables, condoms, and intrauterine devices/IUDs), but 48.4 percent of women using contraceptives choose the pill. For almost two decades, the NFPP has worked to promote the use of IUDs and injectables (two longterm methods) through staff training, reduction of the IUD cost, and involvement of private sector physicians in a social marketing program. Despite these efforts, the oral contraceptive pill remains the most used among the modern methods (85.8 percent), while the use of IUDs and injectables is low (7.4 percent and 2.29 percent, respectively).
As these strategies have reached their limits, introduction of the contraceptive implant was necessary. Indeed, the implant's characteristics make it a good alternative to other long term methods, because it is a hormonal, progestogenic, long-lasting, and easily observable contraceptive method. Thus to ensure an informed voluntary choice and to diversify the available contraceptive methods, including long-term methods, the $\mathrm{MoH}$ introduced the contraceptive implant as part of a pilot project in 2013-2016 in two centers for reproductive health located in Casablanca and Fes [1].

\section{Methodology}

The MoH, with the support of the United Nations Population Fund (UNFPA), implemented a pilot project to introduce contraceptive implants. The project started at two sites located in the cities of Casablanca and Fes. The project lasted three years (December 2013-December 2016) and was externally evaluated in December 2016. This allowed for a stocktaking of the project's quantitative and qualitative outcomes. In conjunction with this evaluation, an action plan was proposed to extend the contraceptive implant to other regions of Morocco.

The pilot project was designed in a participatory manner through workshops organized by the $\mathrm{MoH}$ and involving managers and health service providers. The objective of these workshops 
was to involve the various actors in the project, to validate it, adapt the World Health Organization's eligibility implant criteria to the national context, and finally to validate the launch and followup materials. The MoH team at the central level carried out the follow-up of the project throughout the three years through field visits, technical supervision, and mentoring managers at the pilot sites.

The organization of implant delivery in the project sites in Casablanca and Fes was carried out at three levels: Primary health care centers, the Reproductive Health Referral Center (CRSR), and the University Hospital Center, as follows:

a) Female candidates were recruited at primary health care centers for use of the contraceptive implant. A nurse performed general contraceptive counseling; once the candidate chose to use an implant, she was referred to the CRSR.

b) The CRSR offered specific implant counseling, examination, insertion, management of side effects, and removal. If necessary, reference was made to the University Hospital Center. General practitioners were the lead actor for insertion and removal of the implant and management of side effects.

c) The University Hospital Center employed obstetric gynecology professors who had participated in the project and training implementation; these referents were available to respond to providers' demands as needed in case of difficulties or complications.

The implant insertion and removal kits comprised small equipment that was available at both pilot sites and contraceptive implants were also available. Stock management followed the same procedures as those used for pharmaceutical products of the CRSR. CRSRs are regularly supplied as needed and the nurse in charge of the CRSR provides doctors as needed.
Project training in implant technology comprised three modules:
a) counseling training
b) implant insertion and removal training
c) prevention of infection and its complications

Training was cascaded: first trainers were trained, followed by training of providers. Implant training consisted of three steps:

a) upgrading knowledge of contraceptive implants

b) practical work on an anatomical arm for implant insertion and removal

c) insertion practice on women who chose the implant

Several documents were prepared within the framework of the project based on international norms and standards. The criteria for indication and contraindication of the contraceptive implant method were based on the WHO eligibility criteria adapted to the Moroccan context. Communication support, namely a laminated cardboard and a leaflet containing the information to be communicated to women, was developed. Information on the implant was made available in Arabic and French. For the information system, the following documents were developed: client files, admission form, follow-up sheet, and a registry of women recruited for the implant. An elaborate computerized database allowed for data to be obtained on implant users.

The operational research project carried out in partnership between the MoH and UNFPA costed a total of 655,572 dirhams (US\$70,491). The cost of training, equipment, and other costs were not included in the study. The implant unit cost amounts to 185 dirhams (US\$20) for three years of use, versus 114 dirhams (US\$12) for a combined oral contraceptive and micro-progestin pill, 99 dirhams (US\$10.6) for injectables, and 8.7 dirhams (US\$0.9) for the IUD (Tcu380) (see Table I).

Table 1: Cost of contraceptive methods for the Moroccan $\mathrm{MoH}$ (US\$)

\begin{tabular}{|c|c|c|c|c|c|}
\hline Méthodes & Duration of Use & Cost of 1 Cycle & If Used for 1 Year & If Used for 2 Years & If Used for 3 Years \\
\hline Pilule COC $0,3 \$$ & $\begin{array}{c}1 \text { plaquette à } 0,3 \$ \text { pour } \\
1 \text { mois }\end{array}$ & $0,3 \$$ & $4 \$$ & $8,2 \$$ & $12,3 \$$ \\
\hline Pilule PMP 0,3\$ & $\begin{array}{c}1 \text { plaquette } 0,3 \$ \text { pour } \\
1 \text { mois }\end{array}$ & $0,3 \$$ & $4 \$$ & $8,2 \$$ & $12,3 \$$ \\
\hline Injectable $0,88 \$$ & $\begin{array}{c}1 \text { dose } 0,88 \$ \text { utilisé en } \\
3 \text { mois }\end{array}$ & $0,3 \$$ & $3,5 \$$ & $7 \$$ & $10,6 \$$ \\
\hline IUD unité $0,93 \$$ & $\begin{array}{c}1 \text { DIU à } 0,93 \$ \\
\text { utilisable } 10 \text { ans }\end{array}$ & $0,007 \$$ & $0,93 \$$ & $0,93 \$$ & $0,93 \$$ \\
\hline Implant $20 \$$ & $\begin{array}{l}1 \text { implant à } 20 \$ \\
\text { utilisable } 3 \text { ans }\end{array}$ & $0,5 \$$ & $20 \$$ & $20 \$$ & $20 \$$ \\
\hline
\end{tabular}

Note: $\mathrm{COC}=$ combined oral contraceptive, $\mathrm{PMP}=$ micro-progestin pill, IUD = Intrauterine device.

If implant use is considered over three years, its monthly cost is 5 dirhams (US\$0.5) (this does not take into account the cost of training). The monthly cost of the pill is about 3 dirhams (US\$0.3), and the cost of injectables is 2.75 dirhams (US\$0.3) per month.
Over a three-year period, the cost of an implant is 38 percent higher than that of the pill (the reference contraception for NFPP in Morocco). (see Figure I). 


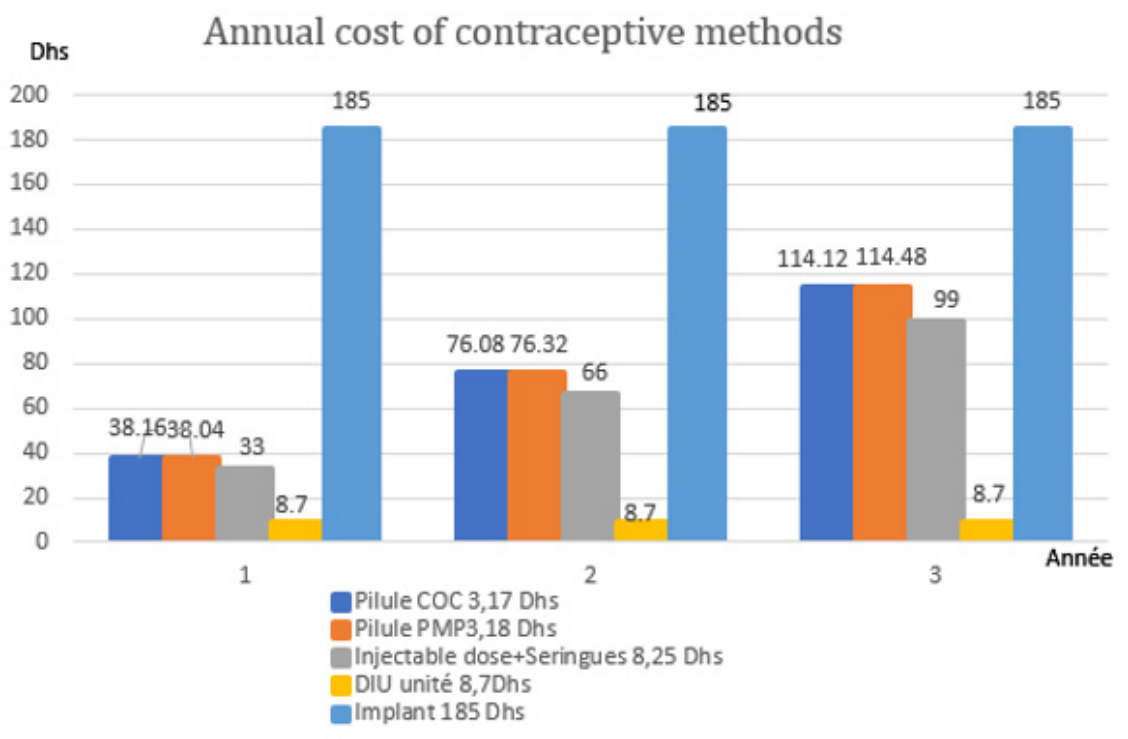

Figure 1: Annual cost of contraceptive methods.

\section{Result}

The objectives of the project evaluation were to analyze the data and propose a large-scale extension in Morocco. The study was designed to follow a cohort of women implant users over three years (2013-2016) and involved 673 women (336 in Casablanca and 337 in Fes). The evaluation was based on document analysis, interviews with project stakeholders, visits to project sites, and focus groups with women using the implant. The results of the pilot project were analyzed both quantitatively and qualitatively.

\section{Quantitative Results}

The average recruitment rate of implant users per year, in a population of Married Woman of Reproductive Age (MWRA) between 15 and 49 years, was 0.20 percent in the pilot site of Casablanca and 0.065 percent in Fes. The study revealed the following:

a. The average age of implant users was 30 years; these women had 2.64 children on average; and 23.8 percent of these women were breastfeeding.

b. Of the new contraceptive implant users: Two-thirds previously used a contraceptive pill (15 percent under a micro-progestin-only pill).

c. The body mass index (BMI) of contraceptive implant users was calculated. Beyond a BMI of $32 \mathrm{~kg} / \mathrm{m} 2$, there is a risk of pregnancy when using an implant. One-quarter of women had a BMI between $30-46 \mathrm{~kg} / \mathrm{m} 2$. The serum concentration of etonogestrel (the progestin used in the implant) is inversely proportional to BMI. This situation limits the duration of implant use to two years instead of three years.

d. The majority of insertions were made at the time when they are effectively registered: 77 percent of insertions were performed in the first five days of the menstrual cycle; 21 percent were inserted between 5-10 days.

e. General practitioners performed 92 percent of the implant insertions; gynecologists performed 8 percent of the insertions, for difficult cases.

f. Women's routine follow-up visits were as follows: 93 percent were seen on the seventh day after insertion for wound healing control; 76 percent visited at three months; 45 percent visited at six months; 22 percent visited at one year; and 10 percent visited in the second year.

\section{Qualitative Results}

The project focused its implementation according to three indicators of quality of service:

A. Indicator 1: Implant effectiveness according to the Pearl Index. The implant effectiveness for women's series in Casablanca and Fes was 100 percent. It is well known that the contraceptive implant is very effective: the implant Pearl Index (number of pregnancies per 100 women in a year) is 0.05 to 0.10 . This effectiveness is due to the observance of this method, which does not depend on users' compliance. According to the data, causes of pregnancy in case of failure were due to four reasons: a technical error, use of an enzymatic inducer drug, failure to respect the BMI limit for implant insertion, and failure to observe the recommended time of implant placement in relation to the menstrual cycle.

B. Indicator 2: Continuity of use. The continuity rate reflects the quality of specific counseling and consolidation. In the pilot series, the premature rate of implant removal at two years was 14 percent, so the continuity rate was 86 percent. 
C. Indicator 3: The rate of local complications. There was a description of one case of granuloma, which was an exceptional local complication.

\section{Lessons Learned}

According to the experience of countries that have introduced the contraceptive implant, two approaches exist for implant introduction into FP programs:

a) Some countries introduce it for a restricted population of women with specific indications for this method and to diversify the range of contraceptive methods proposed for couples

b) Other countries propose it as a strategic method for mass contraception.

The NFPP in Morocco chose the first approach: the implant is an alternative to the available methods offered. In the project, twothirds of women replaced oral contraception with the implant and one-sixth of implant users were first-time contraceptive users. The implant is thus an option to reduce Family planning unmet need.

a. The project was implemented in a participatory and consensual manner during its different stages, ensuring the support of different project actors and contributing to overall project success. Nevertheless, project management was done centrally, which is acceptable for a pilot project but not feasible for an expansion. Regional health departments should be involved in the larger rollout of the project.

b. During project implementation, the standardization of procedures and communication support ensured quality services, as reflected in the quality indicators and the rate of implant continuity (86 percent at two years); this rate is considered high compared to the average published series.

c. It is important to make all contraceptive methods available in the FP service delivery point to ensure an informed voluntary choice. d. Using general practitioners for implant delivery is justified by their availability, the simplicity of the surgical intervention, the adequate training received, and the presence of a referent if necessary.

e. The cost of an implant is about 38 percent higher than that of the pill. However, this doesn't take into account the supply chain management cost and the recurrent service provision cost for oral contraceptives. Considering the costbenefit approach and taking into account compliance with the implant and its effectiveness, its introduction seems warranted.

\section{Conclusion}

a) Essential elements that could contribute to the replication and scale-up of this technique are as follows: political will and commitment; continued financial support for the purchase of contraceptive implants from the state budget; continued training of providers and training at the University Hospital Center for the three modules (implant, counseling, and prevention of infection); and better coordination between the three referral levels.

b) Following this evaluation, the introduction of implant among the basket of FP methods available in Morocco was adopted by the NFPP with strong political commitment and financial support for the purchase of contraceptive implants from the state budget.

c) Currently, in 2019 : (1) the implant is included in the list of contraceptives procured by the NFPP, (2) continuous training for providers is scheduled at the regional level in cooperation between the MOH and UNFPA, and better coordination between the three reference levels is established.

\section{References}

1. http://www.emro.who.int/mor/morocco-news/resultats-delenquete-nationale-sur-la-population-et-la-sante-familialeenpsf-2018.html

\section{Your next submission with Juniper Publishers will reach you the below assets}

- Quality Editorial service

- Swift Peer Review

- Reprints availability

- E-prints Service

- Manuscript Podcast for convenient understanding

- Global attainment for your research

- Manuscript accessibility in different formats

( Pdf, E-pub, Full Text, Audio)

- Unceasing customer service

Track the below URL for one-step submission https://juniperpublishers.com/online-submission.php 